\title{
Fear of Flying (fear of losing control): a case discussion
}

\author{
Nimrat Singh \\ Practicing Clinical Psychologist \\ Corresponding author: Nimrat Singh \\ Email-nimrat@tangramhr.com
}

\begin{abstract}
The paper examines the philosophy and technique of the Intensive Short Term Dynamic Psychotherapy (ISTDP) developed through empirical, video recorded research by Habib Davanloo, from 1960's to 1990's [1]. It is rooted in classical psychoanalysis and focuses on uncovering unconscious mental processes. Yet, it is comprehensive and efficient to remove symptoms and demonstrate long lasting changes in patients in short time. In ISTDP, experience of core emotions from the past are the transformative vehicle and the therapist uses very active ways to unlock the unconscious and thereby bring about a lasting change in the patient. ISTDP, has a very promising future and is being practiced across the world and has earned recognition for being scientific and a 'here and now' experiential therapy that brings about lasting changes. ISTDP defines each of these terms - feeling, anxiety, and defense - differently (triangle of conflict) and the understanding results in techniques and approaches that can often lead to a more rapid and effective level of change. The paper examines the vignette of a 29 years old woman, who developed a fear of flying. Her fear was rooted in her childhood trauma of being abandoned and her repetitive pattern of abandoning her current relationships. Insights into her pattern using the ISTDP therapy, helped her to understand her panic attacks and her fear of flying was markedly reduced. Her relationships improved and she was able to see her internal conflicts and how it affected her marriage.
\end{abstract}

Key words: Intensive Short Term Dynamic Psychotherapy, feelings, anxiety, defenses, triangle of conflict.

(Paper received $-14^{\text {th }}$ November 2018 , Peer review completed $-29^{\text {th }}$ December 2018)

(Accepted $-30^{\text {th }}$ December 2018)

\section{INTRODUCTION}

What causes suffering? Ever since the Buddha, hundreds of answers have been offered and over four hundred therapies! And each of these answers, whether maladaptive cognitions, maladaptive behaviors, unconscious conflict, dysregulated anxiety, etc. is an important piece of that 'puzzle' we call the human person. This question is even significant given the multitude of physical and mental disorders of modern living. ISTDP intersects with Buddhism in their shared finding that defenses cause suffering because they always function as a resistance to facing emotional reality in this moment. And like Buddhism, ISTDP holds that pain is inevitable in life. Every time we love, we will be hurt either by disappointments or through death. Pain is something we must bear; it cannot be removed, simply felt. But suffering, which is caused by our defences, is something we can overcome in therapy [1-2]

Patients come to therapy because they suffer from symptoms and presenting problems. To end this suffering, we must find out what causes it. So, we ask the patient what problems they are seeking our help for. Then, we explore a specific situation where their problem occurs. By exploring, we find out what feeling they avoid due to anxiety and the defences that cause their suffering. Now, we can help the patient see what they must do in therapy: 1) see and turn against defences that create the presenting problems and symptoms; 2) face rather than avoid what makes them anxious; and 3) feel their previously avoided feelings. If they can face and feel their feelings, they don't have to suffer from anxiety and symptoms instead. They can channel their feelings into adaptive action rather than use maladaptive defences. So instead of turning anger inward 
and feeling sad, the patient is taught to regulate their anxiety and reach their feelings of anger they withheld from their childhood toward their significant others and thereby learnt very early in life to mask their true feelings.

\section{Past Experience and Present Symptom}

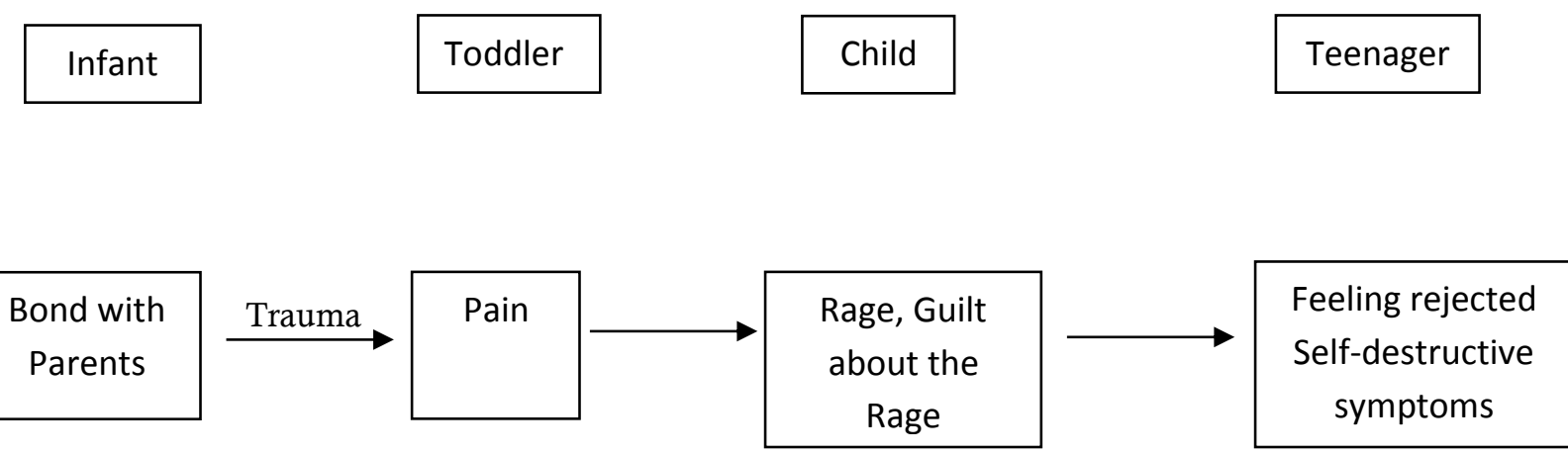

Most patients have been hurt in past relationships. But therapy invites a close relationship. Our invitation triggers feeling, anxiety, and defences in the patient. In our studies, of session videotapes we notice patients can use as many as five defences per minute! And with three hundred defences an hour all day long, it should be no surprise that patients suffer from the symptoms and presenting problems created by those defences. In ISTDP, defence interruption is viewed as an act of compassion toward the patient. Accepting defences in the session collaborates with destructiveness.

Davanloo [3] discovered three basic unconscious pathways for anxiety discharge in the body. When patients get anxious, their anxiety can be discharged into striated muscles, smooth muscles, or cognitive perceptual disruption. And each of these pathways of anxiety discharge has important implications for how to do therapy.

Patients who experience their anxiety in the striated muscles become tense in the session and sigh when you ask about emotionally important material. These patients are usually aware of their anxiety and know what triggers it. These patients can tolerate a high rise of feeling. On the other hand, some patients suffer from anxiety that is discharged into the smooth muscles. They suffer from migraine headaches, upset stomach, and diarrhea. Or patients may experience anxiety discharged into cognitive perceptual disruption. When they become anxious patients, whose anxiety is discharged in this pathway become dizzy, have blurry vision or ringing in the ears, dissociate, or lose track of their thoughts. Patients whose anxiety is discharged into the smooth muscles or cognitive perceptual disruption require anxiety regulation before we explore their feelings. To assess patients' anxiety we must explore their feelings in therapy. Exploring feeling in the session triggers anxiety in the body so we can observe where in the body the patient's anxiety is discharged. With this background information about ISTDP, I am presenting a summary of two sessions I recently had with a client. The below vignette is a summary of 200 minutes of therapy. The key parts of the session have been arranged sequentially in her verbatim

\section{CASE VIGNETTE}

A 29 years old woman working for a social media company came to Tangram on $9^{\text {th }}$ Nov 2017 seeking help because she had to fly to Kolkata the next morning and was very anxious about taking this flight. One month back, she had a panic attack on flight. She was flying Ahmedabad - Delhi and could hardly breathe. She pleaded for help and finally fell asleep till she landed. This episode left a mark on her and she relives it every time she flies. She is a frequent flier. Her parents live in Kolkata and her husband and family live in Ahmedabad. She lived in Kolkata for one year, as she was contemplating divorce. However, after rounds of talks and father's convincing her to patch up, she has been spending quite some time in Ahmedabad. She has a 5 years old daughter, who is very attached to her paternal grandparents. She is planning to shift back by the start of December. 


\section{Psychodiagnostics}

Her anxiety was mostly in the striated muscles. Hence, she was able to well regulate her anxiety and the therapist could invite her to look at her feelings. She used gaze avoidance, distancing, intellectualization and vagueness as her key defences. She was fidgety and restless and sighed from time to time. She was detached and avoided eye contact. She was willing and open to seeking help. The therapeutic alliance was well established. However, key resistance she used was omnipotent transference. 'You can help me, and I know so'. She was reminded about her engagement in therapy and effort are most important. She could easily trust but remained detached.

\section{Part 1}

She did not know what help she needed at the start of the session. Hence, the therapist listened to her disturbances and yet kept asking her -

Therapist: 'What is the emotional issue you need to be helped with?'

Client: 'Nothing, All I know is that I need to fly home tomorrow morning.'

Therapist: 'Since you have no identified emotional issues, I can't really help you?'

Client: 'I really don't know why I am here'.

Therapist: 'And yet, you took an appointment yesterday, and physically walked into a therapist's clinic to seek help. And you don't know why?'

Client: 'I am going on a holiday with my parents. The thought of taking the flight induces fear and anxiety.'

Therapist: 'In that what you want to work with today? Do you have the will to look into this?'

Client: 'I want to know, why I had a panic attack a month back.'

Therapist: 'Only you would know! But if you choose to, we can look at it together.

Client: 'I am willing to.' (Sigh)

Therapist: 'What feelings are coming up right now as of talked about flying? Can you take a look?'

Client: (another sigh). 'I feel very choked and my chest feels constricted. I am breathing very shallow. I recall the time, when I was flying. I had to leave my child behind. But, I love my parents and can't live without them. I was worried for my father. Even, if he has a cold - I think of the worst and want to leave everything and be with him.' (She declared her internal problem and was willing to work with her fears of flying. Now, we needed a specific example of how she experienced panic while flying.)

\section{Part 2}

Therapist: 'What do you recall of the flight?'

Client: 'As I sat, I feel gripped by anxiety. I felt someone was choking my throat. I couldn't breathe. I insisted to the air hostess for a medicine and created a panic in flight. I was made to calm down, and slowly felt asleep. As soon as, I alighted the aircraft I called up my husband to tell him, that I am dying and I am sorry for all that I've done - I have troubled you a lot.'

Therapist: 'Then, how did you calm down?'

Client: 'It happened on its own. But, that really scared me.' 'I have to take flights very often and can't afford to have a flying phobia. I need help.'

Therapist: 'Can we look at what's happening?'

Client: (smooth muscles anxiety) 'My breathe is getting shallow and my chest is constricting again. I feel worried about my father. I don't want anyone to die.' (Breaks down). 'I don't want to grow old, and I don't want my parents to grow old. I want to control everything.'

Therapist: 'Yet, growing old and dying is a reality. You want to live in fantasy. Do you?'

Client: 'I don't care (crying). I cannot bear losing my father.'

Therapist: 'Is he unwell? How old is he?'

Client: 'He is well and 64, but I worry for him.'

Therapist: 'It looks like you have a need to control things? - How does that work for you?'

Client: 'Yes, you are right! I control things at work too. I am very blunt and hurt people but say what is right. I am not sure of my own performance yet I got the highest increment in my office. I work very hard, I have a great client relationship. My boss is super happy with me.' 
She has stated that her fear of flying is related to her losing control. Hence, she feels throttled and breathless on flights.

Therapist: 'Where else does this happen?'

Client: 'With all, at home too! I lost it with my father when he was finding a spouse for my younger sister. I asked him to chill. It was too early for her to marry. He remarked - You should not talk about marriage you stay out and look after yours? I yelled at him, abused him and warned my mother to keep him away.'

Therapist: 'Then what?'

Client: The next thought was - 'What if he gets a heart attack and dies. I will be responsible for his death.'

Therapist: 'So, your superego assaulted you and what did you do?'

Client: 'I, Apologized and got into a panic state.'

Therapist: 'So it looks like that, out of impulse you blow the roof off and blast the person. In some time, start to understand what you did. Judge your action and yourself (super ego) and then begin to panic how to rectify the situation. Could this be the reason for the panic attack?'

Client: Silent and reflective. After a while - 'I see, what you're saying. I can connect the dots in a way. (Started breathing deeply and sat back in a reflective mood.) So, I can see how my fear and need to control makes me mad and then feel very bad.' 'But, now what should I do about tomorrow?'

\section{End of Session 1}

In the next session, she explored her anger towards her husband and his family. Yet, she did not give herself the permission to experience anger fully. Her superego attacked her every time she experienced anger. On reflection, she realized that it was more to do with her projected anger towards her husband. She went back to the core issue of feeling abandoned, hence abandoning her husband. And then she believed that her husband is abandoning her. This part of vignette highlights her childhood struggle and how it affects her self-esteem and her relationships.

\section{Part 3}

Therapist: 'So what is it you want help for?'

Client: 'I have to travel tomorrow. It's super important. I don't feel like speaking to my husband and my parents. I don't know why marriage is such a great deal? I don't know if everybody go through this bad marriages. Mine is bad.'

Therapist: 'Bad is vague. What's the feeling that comes up?'

Client: (Looks away). 'I am insecure by nature. In my head I've done a sacrifice by leaving my city. His attitude makes me very angry. That ticks me off.'

Therapist: 'How do you feel the anger in your body?'

Client: (Sigh) 'Anger comes and goes out. Right now, I am more like I am lost and confused.' (Defense of vagueness)

Therapist: 'You spoke about anger towards your husband and now you say you are confused. So, could you look at what is happening inside you right now?'

Client: 'Hands are sweating. I can barely breathe. (anxiety in the smooth muscles) My heart is sinking. And, I blurt out and in a fraction of a second, I realized that I have goofed up. And, I want to take back what I said.'

Therapist: 'Notice, you are anxious - hands are sweating, heart is sinking, head is feeling light and if you look beneath the anxiety what feelings could be coming up towards your husband - right now?'

Client: (She starts to readjust her collar) agitated and restless. 'I feel nothing (denial) it's not worth, it's not going to work. I am perpetually thinking of going back (starts to weep)'

Therapist: 'If you don't go to your head, can you closely observe the physiological changes in your body and if you look beneath the changes, what feelings come up towards your husband?'

Client: 'I want to cry. I am choking up.'

Therapist: 'And if you did not take your feelings inside. If you allowed your feelings to come up here - how do you feel the anger in your body towards your husband?'

(Reflective, looks away - Tactile defense)

Indian Journal of Mental Health 2019;6(2) 
Therapist: 'Are you willing to look at your anger towards your husband right now?' Client: 'Yah! Yah!'

She went into a visualization of how she will beat the life out of him and scream hard. Yet, the superego would stab her back. I worked in the current and reflected on her difficulty of experiencing anger.

Therapist: 'I notice that you have a difficulty experiencing your anger. Do you notice that too? She nodded in agreement. What feelings come up here towards me that you need to mask your anger and keep it under check. So what feelings come up here towards me (pressure). Here in this place, and towards me?'

Client: 'I just don't want to get angry. It does no good.'

Therapist: 'And, yet you relaxed yourself in the last session and now. How about being kind to yourself? (Anxiety in the striated muscles) What feelings could be coming here towards me for you to put up this wall of helplessness? And if you continue doing this - what kind of relationship will we create here? And how do you think you will help yourself to overcome your fears of flying and work on your anger towards your husband? So what feelings come up here towards me?'

(Pointed out causality and allowed the patient to reach her feelings. She got restless - striated muscle anxiety) Therapist: 'Notice, how you look away, look down and detach yourself from me here. What feelings could be coming up here towards me to put up this wall of detachment? (Pause)

Yeh! The feelings towards me.' (Pressure to feelings)

Client: 'I know that you can really help me. You will solve my problem.' (resistance of Omnipresence) Blocked the resistance and worked in the $\mathrm{C}$ (current)

Therapist: 'And yet, you detach yourself from me here. And who do you think will help you here?'

Client: 'I myself. You'll help me to help myself.'

Therapist: 'If you put in 10\% in your session, what will you get? (Looked down in disappointment). Notice now you look away, and not allow yourself the freedom to express your feeling here in therapy and experience your anger in a place like this. (She relaxes her neck and relieves the tension). Yet you have feeling and you make a choice to ignore them? Is that the way you ignore your feelings and expect your husband to pay heed your feelings'.

Client: 'I want to scream and shout loud. I am working on being civil.' (Smooth muscle anxiety)

Therapist: 'Is there any evidence, that I want you to be in check of your emotions?

Notice how you judge yourself here?'

Client: 'I don't know why I am angry? (Projection) And I don't want to be angry. I want to scream real loud.'

Therapist: 'You may not physically scream, but you could experience screaming and free yourself. I wonder who is judging you here.'

Client: 'I have always been judged by my husband. He would not take me out, but if I am out with my friend (boy) then I am a bitch and a slut.' (Anger building up)

Therapist: 'He is not here. Am I judging you? Then who is? Notice! How you look away, turn your face. Who is judging you here?'

Client: 'No body. I am trying not to be wild. It's been a while, I don't get angry.'

Therapist: 'Where does the anger go?'

Client: 'In my system.' (Looked down and away).

She sabotages and throttles her feelings and projects it on to the others. The therapist points out the causality and the price. How she detaches herself from her feelings and creates relationships that are distant or controlling.

\section{Part 4}

Therapist: 'Are you saying that you are struggling with your own self, hence are not in a position to deal with marriage and the stresses that come along with it?'

Client: 'Yes! A midlife crisis may be there at a personal level, I really don't know what I want. But I want to go to club night, be fashionable, party, drink, and I want to give time to my daughter too.'

Therapist: 'Would you like to look at the conflict within?'

Therapist: 'Notice your involvement in therapy is sporadic too. Both the times, you came on demand of an immediate appointment because you needed to travel.' 
Notice what you do - life is at your terms. Hence, what message do you give to others? And does it become a problem between you and others. Do you see it?'

Client: 'It is a problem. If things are not going my way, I switch over.'

Therapist: 'What would you like to do with it?'

Client: 'Since childhood, I have always had it my way. I have no idea what normal people do.'

Therapist: 'Is it a problem for you?'

Client: 'As long as my parents and my best friends are concerned, I will have it my way. I know it won't last for ever. That is why again and again, I need to go back to the comfort of my friends and parents. That gives me the confidence to go back home. I don't know what a 'no' means I can say a 'no' but can't hear one. I want to work with my anxiety and insecurity that is eating me.'

Client: (Pauses and continues reflecting) 'There are at times, I am not anxious at all. A month back, I got the first panic attack. I could barely breathe in the aerobridge. On flight I only like the isle seat. The moment I have no place to move, I feel panic and anxiety. I just have to be in control.'

Therapist: 'Isn't this exactly what happening in your real life. The moment your husband or in laws don't let you have your ways, you want to take off and move to the safety of your parents.

(She nodded- clearly understanding) The moment your freedom is taken away, you feel throttled and that is how the symptom of choking and smothering come up.'

\section{Part 5}

Therapist: 'What else do you remember? Probably in your childhood - where you could have been with people you didn't want to be with. You were stuck...'

Client: (Could recall immediately). 'I was in a bad state. I was being taken. I was crying and wanted to jump out of the train. My father sent me with his sister. I was told it's just a vacation. On that train I figured it was not a holiday. I cried to come back home. Nobody did let me go back home.

My dad fired me for her. I was 8 years. My Bua's son died when he was of my age. (She broke down). I was brought to Ahmedabad as a child. I hated school. I used to hit Bua and abuse her. I fell sick and then they had to send me home. They couldn't control me. I was a wreck. I hated my mother. Only my maid could take care of me. I recall another incident when I was in class VI, I wanted to watch a movie so my parents left me with my maternal grandparents. They left me there and I threw a fit. They had to come and take me home. Aggression kept building up. It felt nobody wanted me and I was just there. I felt it in school. I was always suspicious about people talking about me. I would feel hurt. The constant feel that parents and husband don't want me.'

Therapist: 'How did you feel towards your father for sending you? It was his sister and he left you to the station.'

Client: 'As a child, I didn't connect this incident to my father. I felt lots of love for him and I hated my mother.'

Therapist: 'Notice! How your anger got displaced from your father to your mother.'

Client: 'That's because one aunty told me that I was sent because my mother hated me. She used to hit me a lot when I was a child. I was a wreck. Today, if somebody behaved like this with me - I would have slapped that child.

My younger sister (3 years younger) understands me totally. I put my head on her lap. She loves me. My sister and daughter don't judge me. Parents are cautious. My mom understands me more than my father.'

Therapist: 'Do you forgive her?'

Client: 'Absolutely, but she did have a say. How can my husband give away my daughter without my permission?'

Therapist: 'It's it possible that you had anger towards your father, mother and your Bhua and feeling of being abandoned continues in other relation too. Is it possible?'

Client: 'I feel really angry with my father because he still doesn't get what that separation did to me at that age. Do you realise he ruined my childhood.'

Therapist: 'How do you feel towards him?'

Client: 'Angry (voice was angry and she looked angry) do you realise your sister was an adult - you goofed up and ruined not only my 4 months but my life. But all my life, I had miserable relationships with all people 
- especially with men. I have picked all the wrong men all my life. Why? Because I was seeking attention and because attention didn't come from home. You made the mistake. You are responsible. 3 minutes on STD was all I had of you in my childhood. My mom had anger issues. I was beaten up and I threw fits. I used to throw plates in anger.'

Therapist: 'How did this young child of 8 feel when she was handpicked and choose to be the sacrificial lamb because her father wanted to comfort her sister? How would you be able to make sense to the child? Hell would have broken loose for her.' The session ended with her reaching out to that little girl of 8 and feeling the plight of the child abandoned many times. She could experience her anger towards her father, mother and Bhua. Her Body-neck, shoulder felt better by the end of the session. Her breath normalised and she was ready to take her next flight although still anxious about it.

\section{CONCLUSION}

Human beings are wired for attachment. When attachments get disrupted without repair, it gives rise to relational trauma. This trauma has psychological and interpersonal consequences. If the child is unable to process these feelings of abandonment with the significant others, she avoids feelings and relationships that trigger them even in adult life. As seen in the above vignette, the client continued to remain detached from her husband and other relationships. Her relationships with her parents was based on unhealthy dependence, demands and constant need to hurt them. This was followed by guilt and anxiety (panic). She experienced detachment estrangement (her projections) from others. She was unable to express her love to her daughter, parents and husband. Abbas describes the consequences of relational rapture by asserting that a complex set of feelings are triggered by attachment trauma, including rage, guilt about rage, pain, as well as loving and tender feelings at the core of attachment. Sealing all the feelings in an outer psychic layer of defence against emotional closeness with others. 'A child who shuts down her complex feelings can grow into an adolescent who experiences interpersonal avoidance, self-destructiveness, depression and anxiety [7].

Acknowledgements - Gratitude to my mentors / supervisors - Jon Frederickson and Thomas M. Brod for introducing me and constantly guiding me in my quest to know more of the theory and practise of ISTDP.

\section{REFERENCES AND RECOMMENDED READING}

1. Frederickson J. Lies We Tell Ourselves: How to Face the Truth, Accept Yourself, and Create a Better Life. Seven Leaves Press; 2017.

2. Davanloo H. Short-term dynamic psychotherapy. Jason Aronson; 1980.

3. Davanloo H. Intensive short-term dynamic psychotherapy: selected papers of Habib Davanloo. John Wiley \& Sons Inc; 2001.

4. Grecucci A, Chiffi D, Di Marzio F, Job R, Frederickson J. Anxiety and its regulation: neural mechanisms and regulation techniques according to the experiential-dynamic approach. In New Developments in Anxiety Disorders 2016 Dec 7. IntechOpen.

5. Freud S. Mourning and melancholia. General psychological theory. Basic Books; 1917.

6. Malan D. Beyond Interpretation: Initial Evaluation and Technique in Short- Term Dynamic Psychotherapy. Part I. Int J Intensive Short- Term Dynam Psychother 2000;14(3):59-82.

7. Abbass A. Reaching through resistance: Advanced psychotherapy techniques. Kansas City, MO: Seven Leaves Press; 2015.

8. Neborsky R. Treatment of trauma using an affect-experiencing - attachment theory approach. In M. F. Solomon, \& D. J. Si Neborsky RJ. A clinical model for the comprehensive treatment of trauma using an affect experiencing-attachment theory approach. Healing trauma: Attachment, Mind, Body and Brain;. 2003

9. Courtois CA, Ford JD. Treatment of complex trauma: A sequenced, relationship-based approach. Guilford Press; 2012.

10. Siegel DJ, Solomon M, editors. Healing Trauma: Attachment, Mind, Body and Brain (Norton Series on Interpersonal Neurobiology). WW Norton \& Company; 2003.

11. Singh N. Are Depression and Anger Two Sides of the Same Coin. Indian Journal of Mental Health 2018;5(3): 342-8.

Funding - Nil; Conflict of Interest - Nil 